\title{
Chemical Transformation of Individual Asian Dust Particles Estimated by the Novel Double Detector System of Micro-PIXE
}

\author{
Chang-Jin Ma* \\ Department of Environmental Science, Fukuoka Women's University, Fukuoka 813-8529, Japan \\ *Corresponding author. Tel: +81-92-661-2411, E-mail: ma@fwu.ac.jp
}

\begin{abstract}
By the application of novel double detector system of micro-PIXE that can detect light elements $(Z<14)$, we made an attempt to provide a thorough discussion on the aging processes of Asian dust (hereafter called "AD") particle by reaction with sea-slat. The elemental spectra and maps obtained from the microbeam radiation of micro-PIXE to individual $A D$ particles were useful for fractionating $A D$ particles into both internally and externally mixed particles. A spatial distribution of elements in a minute domain of single particle obtained by scanning the microbeam irradiation enabled us not only to estimate the chemical mixing state of individual $A D$ particles but also to presume their aging processes in both ambient air and cloud. By calculating the normalized micro-PIXE net count of elements, it was possible to classify individual $A D$ particles into three distinct groups (i.e., (1) Aging type 1: AD particle coated by the gaseous $\mathrm{Cl}$ evaporated by the reaction between artificial acids and sea salt; (2) Aging type 2: AD particle mixed with sea salt but no additional reaction with artificial acids; and (3) Non-aged type) A relatively high transformation rate (63.3-75.9\%) was shown in large particles (greater than $5.1 \mu \mathrm{m}$ in diameter).
\end{abstract}

Key words: Asian dust, Micro-PIXE, Single particle, Sea-salt, Light elements, Aging processes

\section{INTRODUCTION}

AD dust storm often occurred at desert and loess areas in northwest of China traverse Chinese continent and can be extended to Pacific Ocean to pass through Korea and Japan in every spring time. Because of many uncertainties, the mechanisms of $\mathrm{AD}$ outflow, transportation, and natural removing process needs to be fully investigated. This uncertainty is because of lack of long-term and systematic observational data, especially lack of studies of physicochemical changes of $\mathrm{AD}$ during its long-range transportation. During long-range transport of air masses containing AD particles over oceans, AD particles can capture gases or coagulate solid particles and react with each other, leading to a change in chemical compositions (Hwang et al., 2008; Ma et al., 2004a; Nishikawa and Kanamori, 1991; Iwasaka et al., 1988; Duce et al., 1980). Zhang et al. (2003) made an investigation for the elemental composition and size of individual AD particles and their mixture state with sea salt, sulfate, and nitrate. They reported that about $60-85 \%$ of dust particles collected at southwestern Japan was internally mixed with sea salt. Chemical transformation of $\mathrm{AD}$ particles can alter the marine ecosystem and radiative properties of dust clouds (Zhang and Iwasaka, 2004). Hwang et al. (2008) reported that AD particles were mixed with sea-salts entrained over the Yellow Sea, as well as air pollutants from the eastern China coastal areas.

Microbeam Particle Induced X-ray Emission(PIXE), often called micro-PIXE, is a variation of PIXE that has become very important in recent years. It is a combination of the microbeam technique with PIXE analysis (Johansson and Campbell, 1988). Its greatest advantages are excellent sensitivity and the absolutely low detection limits $\left(10^{-15}-10^{-16} \mathrm{~g}\right)$. Also it has the merit of being a multielement non-destructive technique with a wide range of elements for various samples. Unlike the Scanning Electron Microscopy coupled with Energy Dispersive X-ray (SEM-EDX), which needs the pretreatment of the samples, micro-PIXE can analyze the original samples without pretreatment (i.e., non-destructive analysis). By scanning the microbeam (in this study, a 1-2 $\mu \mathrm{m}$ beam diameter) on the surface of specimen, it is also possible to visualize the microscale spatial distribution of trace elements independent of sample thickness.

Till now, the experimental results about the individual environmental specimens using micro-PIXE have been reported (Ma et al., 2000; Koltay et al., 1999). 
Although this micro-PIXE has certain advantage over alternative sensitive individual particles measurement methods, e.g., laser microprobe mass spectrometry (LAMMS) (Gieray et al., 1997) and secondary ion mass spectrometry (SIMS) (Odom et al., 1988), as one of the defective points of micro-PIXE, the determination of light elements (atomic number $<14$ ) is not generally realized.

By using micro-PIXE analytical system, Ma et al. (2000) carried out the single particle analysis for the coarse particles collected in an AD storm event. In doing so, they pointed out that the significant $\mathrm{Cl}$ was detected in individual dust particles. However, they did not fully discuss the internal mixing state in view of reaction between dust particles and sea-salts. Because other $\mathrm{Cl}$ sources such as gaseous $\mathrm{Cl}$ and non sea-salt particulate $\mathrm{Cl}$ can also influence on the aging processes of AD particles (Ma et al., 2008). Hence, in order to clearly discuss the mixing processes of $A D$ particles with sea-salts from micro-PIXE data, one should simultaneously analyze $\mathrm{Na}$ in individual $\mathrm{AD}$ particles that were captured at receptor area. However unfortunately, as mentioned above, until now light elements including $\mathrm{Na}$ have not been determined by micro-PIXE. Broadening the range (including $\mathrm{Z}<14$ ) of analyzed elements by micro-PIXE is urgently needed to assess the aging processes of AD particles.

In the present work, an attempt was made to broaden the range of analyzed elements by employing the double detector system at micro-PIXE. Here, we report the preliminary results of the double detector system and its application to the interpretation of the mixing state of individual AD particles with sea-salt.

\section{MATERIALS AND METHODS}

\subsection{Sampling of Ambient AD Particles}

An intensive measurement of ambient AD particles was performed at a ground-based site in Fukuoka, Japan during an AD period in April 2005. Because of its closeness to the Asian mainland, this area can be directly exposed to the outflow of air masses from the Asian continent during springtime (see Fig. 1). Therefore, this area is one of the well suited sites to monitor the occurrences AD in Japan. A ground-based sampling station (with a height of $15 \mathrm{~m}$ above ground) is located at one of the buildings of Fukuoka Women's University $\left(33.40^{\circ} \mathrm{N} ; 130.26^{\circ} \mathrm{E}\right)$ and is marked as an empty square in Fig. 1.

For the sampling of ambient AD particles, a low pressure Andersen impactor (LPAI) samplers (Tokyo Dylec Co., LP-20) was operated on April 20 (12:0015:00), 2005. As one of multi-stage particle sampling

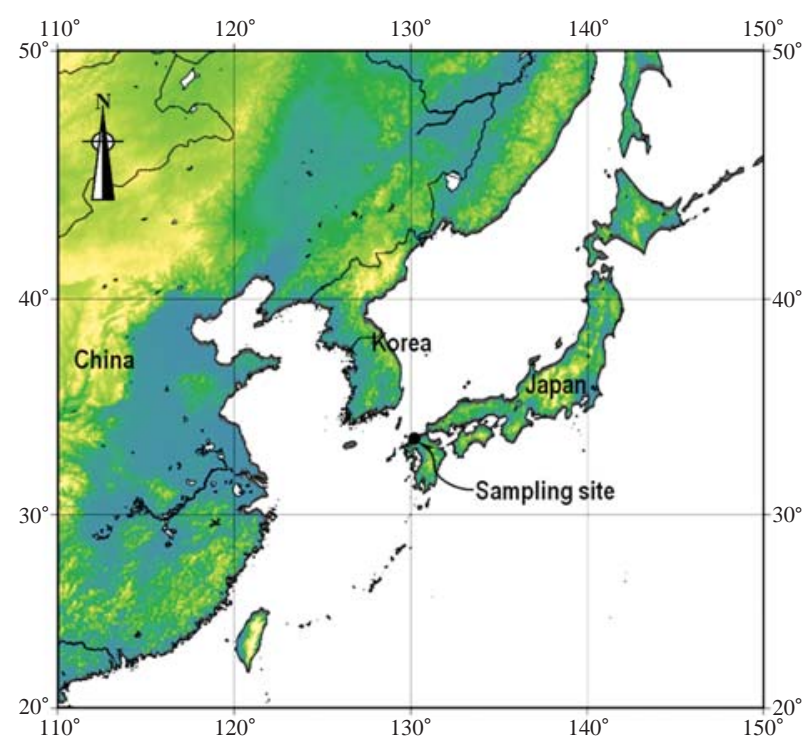

Fig. 1. Map showing the sampling location of ambient AD particles.

instruments, this LPAI with multi-orifice was designed to measure the size distribution and mass concentration of particulate matter. Particles are sampled directly on substrate material $\left(80 \mathrm{~mm}\right.$ diameter Nucleporefilter $\left.{ }^{\circledR}\right)$ arranged behind the jet-nozzles of an impactor. The detailed cut-off particle diameter of each stage for the LPAI was already mentioned in other papers by $\mathrm{Ma} e t$ $a l$. (2004c) and Ma and Kim (2008). During the sampling period, the ranges of temperature and relative humidity (RH) were $18.8-21.7^{\circ} \mathrm{C}$ and $41-56 \%$, respectively.

\subsection{Analytical Method}

\section{2.1 The General of Micro-PIXE}

Micro-PIXE analytical measurements in the present work performed with the facilities of the Takasaki Ion Accelerators for Advanced Radiation Application in Japan atomic energy research institute. The followings are common principle of micro-PIXE analysis.

1. An electron in inner shell jumps with the interaction with a particle beam (in this study, a $2.5 \mathrm{MeV} \mathrm{H}^{+}$ microbeam accelerated by a $3 \mathrm{MV}$ single-end accelerator).

2. Another electron in outer shell moves to an inner orbit.

3. A characteristic X-ray that has particular energy is emitted.

4. Quantity of elements by counting the number of characteristic X-rays

Quantity of an element in a sample can be measured by counting the number of characteristic X-rays. The 


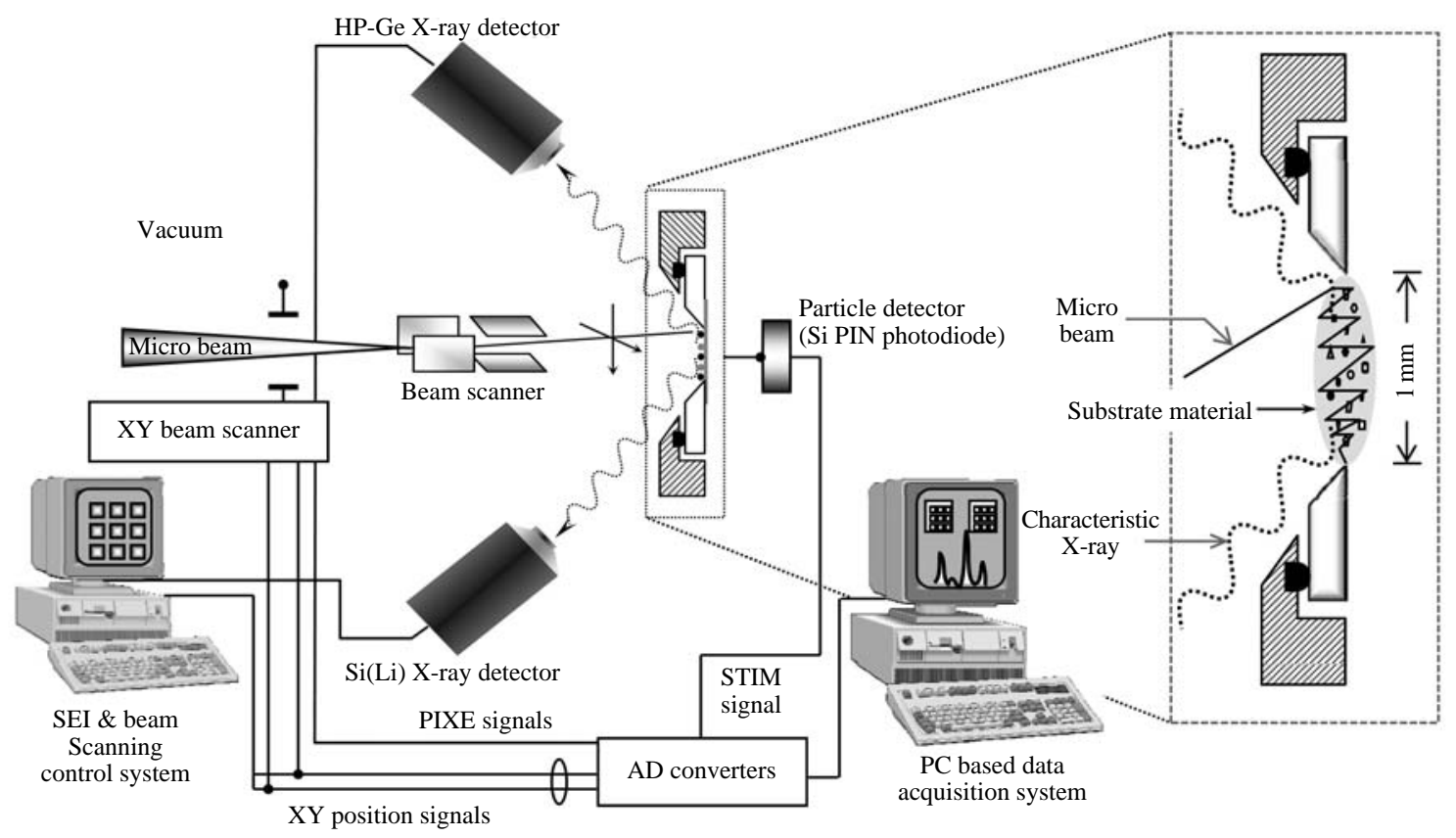

Fig. 2. A schematic diagram of the beam scanning and data acquisition system for micro-PIXE system consisting of the advanced HP-Ge: $\mathrm{Si}(\mathrm{Li}) \mathrm{X}$-ray detectors.

Table 1. Specification of two different X-ray detectors.

\begin{tabular}{lclcccc}
\hline X-ray detector & Model & ${\text { Window }()^{\mathrm{b}}}$ & Absorber & Distance $^{\mathrm{c}}$ & Prioty element & Detectable elements \\
\hline $\mathrm{HP}^{\mathrm{a}}-\mathrm{Ge}$ & IGLET-X-11145 & $\mathrm{Be}(25 \mu \mathrm{m})$ & Polypropylene $60 \mu \mathrm{m}$ & $22 \mathrm{~mm}$ & Middle-Heavy & $\geq \mathrm{Si}$ \\
$\mathrm{Si}(\mathrm{Li})$ & $\mathrm{LS} 30135$ & $\mathrm{Be}(8 \mu \mathrm{m})$ & Mylar $100 \mu \mathrm{m}$ & $18 \mathrm{~mm}$ & Light & $\geq \mathrm{Na}$ \\
\hline
\end{tabular}

${ }^{\mathrm{a}}$ High-purity, ${ }^{\mathrm{b}}$ Thickness, ${ }^{\mathrm{c}}$ Detector-window distance

characteristic X-ray of element A can be calculated by following equation;

$$
\mathrm{Y}_{\mathrm{A}}=\mathrm{N}_{\mathrm{A}} \times \mathrm{Q} \times \mathrm{d} \Omega \times \mathrm{E} \times \mathrm{R}_{\mathrm{a}} \times \sigma^{\mathrm{x}} \times 4 \pi \mathrm{S}^{-1}
$$

where $\mathrm{N}_{\mathrm{A}}$ is the number of element $\mathrm{A}$ in sample, $\mathrm{Q}$ is the total number of incident particle, $d \Omega$ is a solid angle, $\mathrm{E}$ is detecting rate of detector, $\mathrm{R}_{\mathrm{a}}$ is the absorption rate of characteristic X-ray, $\sigma^{\mathrm{x}}$ is a section area of characteristic X-ray generation, $\mathrm{S}$ is beam spot, respectively.

\section{2. 2 The Novel Double Detector System of Micro-PIXE}

Fig. 2 shows a schematic diagram of the beam scanning and data acquisition system of micro-PIXE employing double X-ray detectors and Table 1 indicates the properties of each detector. The HP-Ge X-ray detector has moderate energy resolution and poor detection efficiency below $2 \mathrm{keV}$ because of its Ge L-shell absorption edge and backscattering proton absorber (60 $\mu \mathrm{m}$ thick polypropylene). The $\mathrm{Si}(\mathrm{Li}) \mathrm{X}$-ray detector was set at a symmetrical position with the HP-Ge
$\mathrm{X}$-ray detector with respect to the beam axis. The energy resolution of the $\mathrm{Si}(\mathrm{Li})$ detector is excellent, and this higher energy resolution results in a better signal-to-background ratio and smaller peak overlapping, especially in the low-energy regions. The detector window is $8 \mu \mathrm{m}$-thick Be and attached with an annular type absorber $(100 \mu \mathrm{m}$-thick Mylar) with a center hole (3 $\mathrm{mm}$ in diameter). This $\mathrm{Si}(\mathrm{Li})$ detector can finally provide a fairly good detection efficiency for X-rays below $2 \mathrm{keV}$. Details of this double X-ray detectors system for PIXE Analysis have been described elsewhere (Sakai et al., 2005).

\section{2.3 QA/QC for PIXE Aanalysis}

The energy of an X-ray is converted during the process of charge creation in semiconductor diode to the charge pulse and subsequently after amplification to the voltage pulse. The analog voltage pulse height is converted further to the digital output from the channel number. Channel number $\mathrm{N}_{\mathrm{ch}}$ is linearly proportional to the initial X-ray energy (E) according to relation: 


$$
\mathrm{N}_{\mathrm{ch}}=\mathrm{A}_{1}+\mathrm{A}_{2} \mathrm{E}
$$

Coefficients $A_{1}$ and $A_{2}$ are energy calibration coefficients that define positions of X-ray peaks at the PIXE spectrum. These coefficients are needed for the procedure of fitting theoretical spectrum to experimental one. Since the energy resolution of the $\mathrm{Si}(\mathrm{Li}) \mathrm{X}$-ray detector depends on energy as well, it also has to be calibrated. Usually, peak's full with at half maximum (FWHM) is calibrated, using simple relationship like:

$$
\mathrm{FWHM}=\left(\mathrm{A}_{3}+\mathrm{A}_{4} \mathrm{E}\right)^{1 / 2}
$$

where $\mathrm{A}_{3}$ and $\mathrm{A}_{4}$ are FWHM calibration coefficients which have to be determined (IAEA-TECDOC-1190, 2000).

\section{RESULTS AND DISCUSSION}

\subsection{Inflow of AD Storm}

An isentropic backward-trajectory analysis was carried out in order to obtain the transport path of the dust-storm particles. This backward trajectories for air parcel that arrived at our sampling site calculated by the National Oceanic Atmospheric Administration (NOAA) HYSPLIT (HYbrid Single-Particle Lagrangian Integrated Trajectory) dispersion-trajectory model "backwards" (http://www.arl.noaa.gov) are illustrated in Fig. 3. The prevailing wind on April 20, 2005 was coming from the desert and loess regions in northern China and southern Mongolia. It was extended to the Japanese Island after passing through the domestic areas of China, the Yellow sea, and the Jeju Island, Korea. It could therefore be suggested that the AD particles were long-range transported (i.e., from the dust source areas to the receptor of this study).

A weather chart depicting the meteorological conditions over East Asia area at 09:00 on Apr. 20, 2005 is also piled up Fig. 3. A low pressure accompanying a wide cold front was distributed at west Japan and moved to east. This frontal type and location caused very high speed wind at west side of Japan (a maximum wind speed of $33.9 \mathrm{~m} \mathrm{~s}^{-1}$ at Totori city). And a dense AD covered over all Kyushu area(Japan Meteorological Agency).

\section{2 Visually Classified Individual AD Particles by Micro-PIXE Spectra and Elemental Maps}

An example of the micro-PIXE spectra taken on single AD particle is displayed in Fig. 4. As shown in Fig. 4, by means of the double detectors system of micro-PIXE it was possible to draw the broaden range of analyzed elements including the low $\mathrm{Z}$ elements

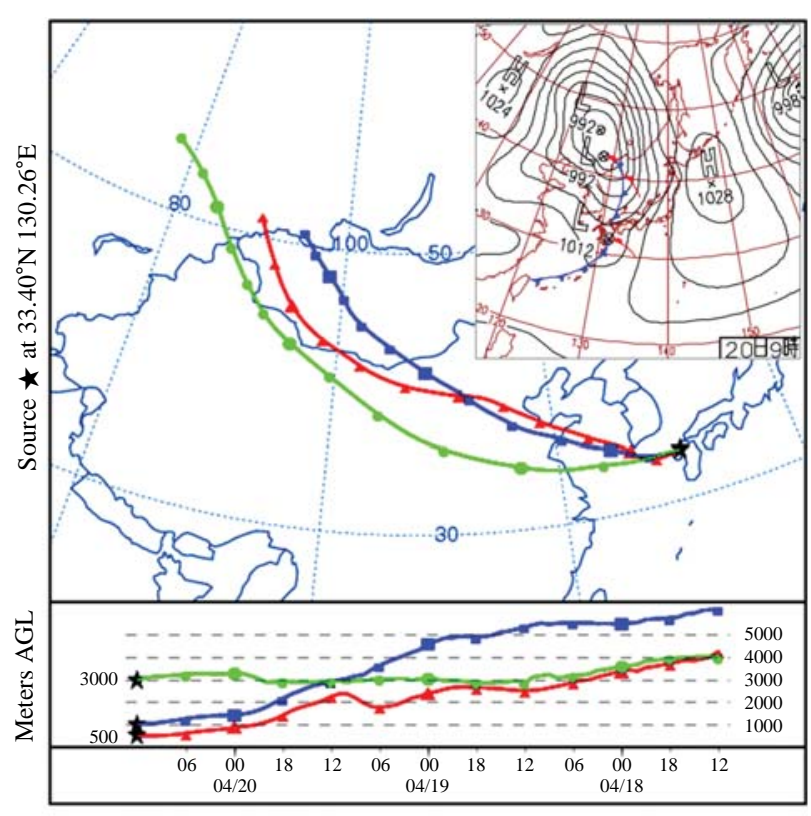

Fig. 3. Backward trajectories drawn by the NOAA HYSPLIT model. Source point $(\star)$ and label interval are $33.40^{\circ} \mathrm{N}$; $130.26^{\circ} \mathrm{E}$ and 6 hours, respectively. Each symbol means meters (triangles: $500 \mathrm{~m}$, squares: $1,000 \mathrm{~m}$, and circles: $3,000 \mathrm{~m}$ ) above model ground level (AGL).

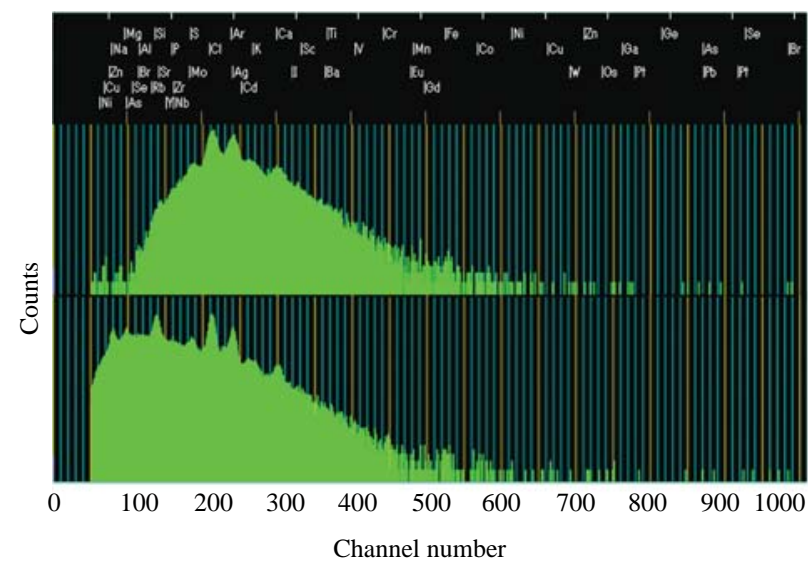

Fig. 4. An example of two kinds micro-PIXE spectra for a $\mathrm{AD}$ particle $(5.07 \mu \mathrm{m}$ aerodynamic diameter). It was driven by a HP-Ge X-ray detector (top) and a $\mathrm{Si}(\mathrm{Li})$ detector (bottom).

( $\geq \mathrm{Si}$ ). Through the combination of two kinds microPIXE spectra we can thoroughly realize the interpretation of the mixing state of individual AD particles with sea-salt.

Fig. 5 shows the micro-PIXE elemental spectra for the seven arrow-marked individual AD particles that were collected on the 2 nd stage $(5.07 \mu \mathrm{m}$ aerodynamic diameter) of LPAI. Outer blackly filled and inner grey- 


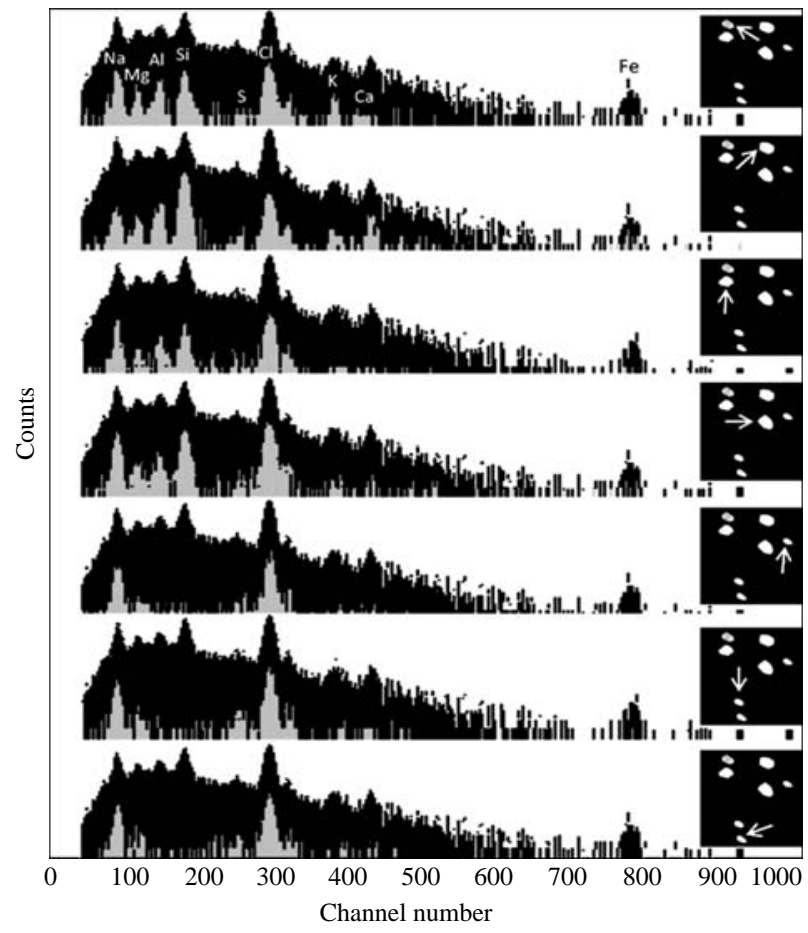

Fig. 5. Micro-PIXE elemental spectra for individual AD particles collected on the 2 nd stage $(5.07 \mu \mathrm{m}$ aerodynamic diameter) of LPAI. ly filled spectra were formed by scanning the whole area retaining seven particles (a blackly filled square at right side of Fig. 5) and each indicated particle, respectively. The scanning of microbeam on each individual particle enabled us to draw more clearly separated peaks of each element including light elements (e.g., $\mathrm{Na}, \mathrm{Mg}$, and $\mathrm{Al}$ ). First of all, the microPIXE spectra displayed in Fig. 5 shows a severe particle-to-particle variation of the elemental composition among individual coarse particles collected during our intensive field measurement campaign.

From the inner greyly filled spectra, individual particles can be classified into two distinct groups (i.e., above four particles (group 1) and below three particles (group 2) groups). In the particles belonged to group 1, $\mathrm{Na}$ and $\mathrm{Cl}$ coexist with soil-derived components such as $\mathrm{Al}, \mathrm{Si}, \mathrm{K}, \mathrm{Ca}$, and $\mathrm{Fe}$. The particles of group 1 are the typical example of internally mixed particles which contain a uniform mixture of components from each of the sources. The coexistence of sea salt and mineral components also indicates that $\mathrm{AD}$ particles were experienced aging processes namely, chemical transformation, in the course of their longrange transport. Whereas, only marine components (e.g., $\mathrm{Na}, \mathrm{Cl}, \mathrm{S}$, and $\mathrm{Mg}$ ) were detected in the particles of group 2 .
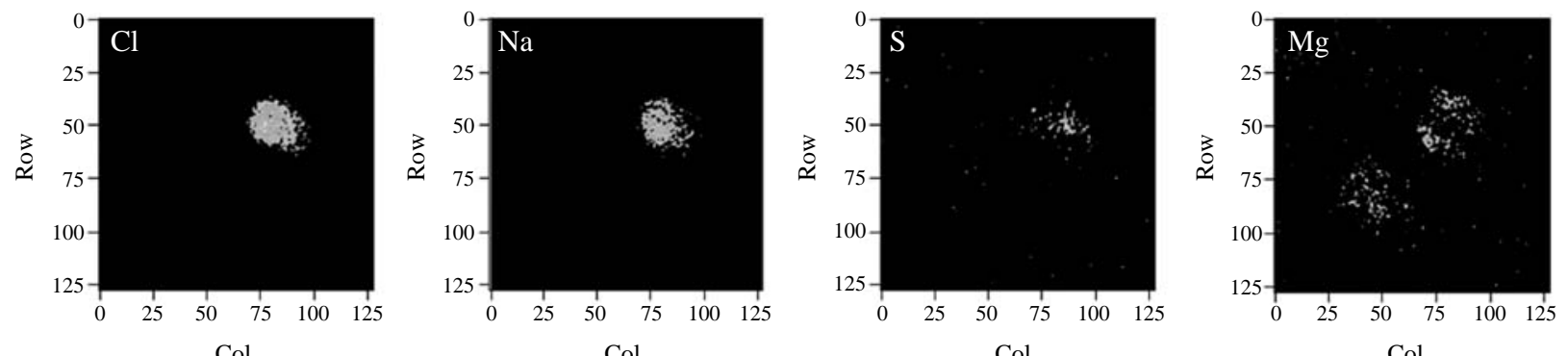

Col

$\mathrm{Col}$
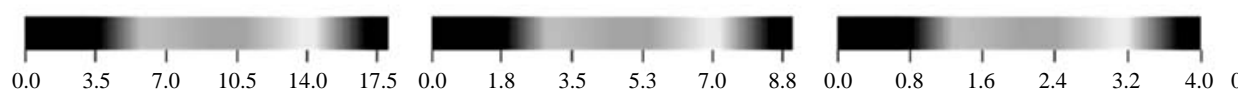

$\mathrm{Col}$
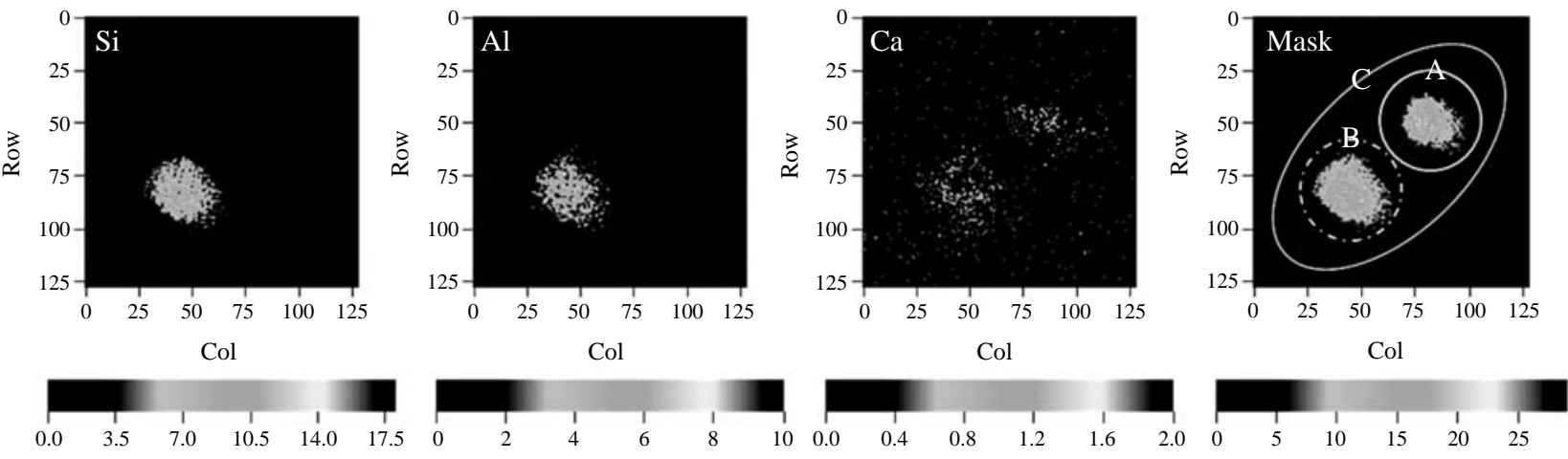

Fig. 6. An example of micro-PIXE elemental maps taken on two particles collected during AD event. Scanning area of microbeam is $25 \times 25 \mu \mathrm{m}^{2}$. 


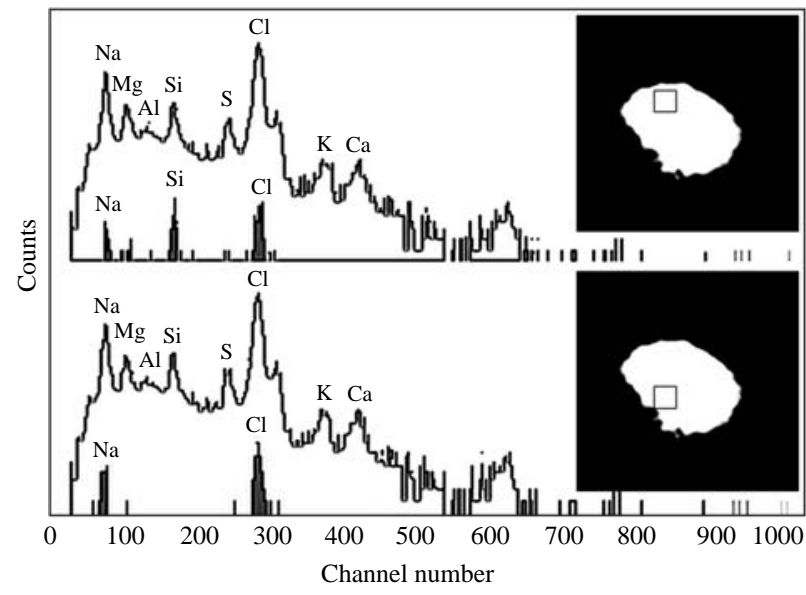

Fig. 7. Micro-PIXE elemental spectra for two different portions of an AD particle.

Fig. 6 displays an example of micro-PIXE elemental maps taken on two particles $(5.07 \mu \mathrm{m}$ aerodynamic diameter) collected during AD event. Two combined masks of total elements are schematically shown on the last insert. The particle displayed at top portion of scanning area is containing marine components (e.g., $\mathrm{Cl}, \mathrm{Na}$, and $\mathrm{S}$ ). Whereas, several crustal elements (e.g., $\mathrm{Si}, \mathrm{Al}$, and $\mathrm{Ca}$ ) are principally distributed in and/or on a particle located at bottom of scanning area. On the other hand, $\mathrm{Mg}$ and $\mathrm{Ca}$, which are minor (or relatively minor) composition in both sea-salt $(\mathrm{Mg}: 0.128$ wt. $\%$ and Ca: 0.0418 wt.\%) and dust sand $(\mathrm{Mg}: 1.57$ wt.\% and Ca: 5.83 wt.\%) (The standards of China loess and Simulated Asian mineral dust, 1998) are weakly coexisting in and/or on two particles. From this elemental map and mask replayed corresponding to individual two particles we can reasonably suggest that two particles are externally mixed particles (i.e., each particle arises from only one source).

Micro-PIXE analysis has the scanning ability of microbeam with a $1-2 \mu \mathrm{m}$ beam spot size. By scanning this microbeam, we can obtain spatial distribution of trace elements in individual particles. As a result, it is possible to know the portion-to-portion variation of elemental compositions in a particle. Fig. 7 shows an example of the micro-PIXE elemental spectra for two different portions of an $\mathrm{AD}$ particle with $5.07 \mu \mathrm{m}$ aerodynamic diameter. Outer white and inner black spectra were formed by scanning the whole and each square portion on a particle, respectively. According to this analytical result, the top portion of particle contains both sea-salt and silicon. However, only seasalt components were detected in the bottom portion of particle. It can therefore be said that the chemically transformed AD particle shows heterogeneous elemen-

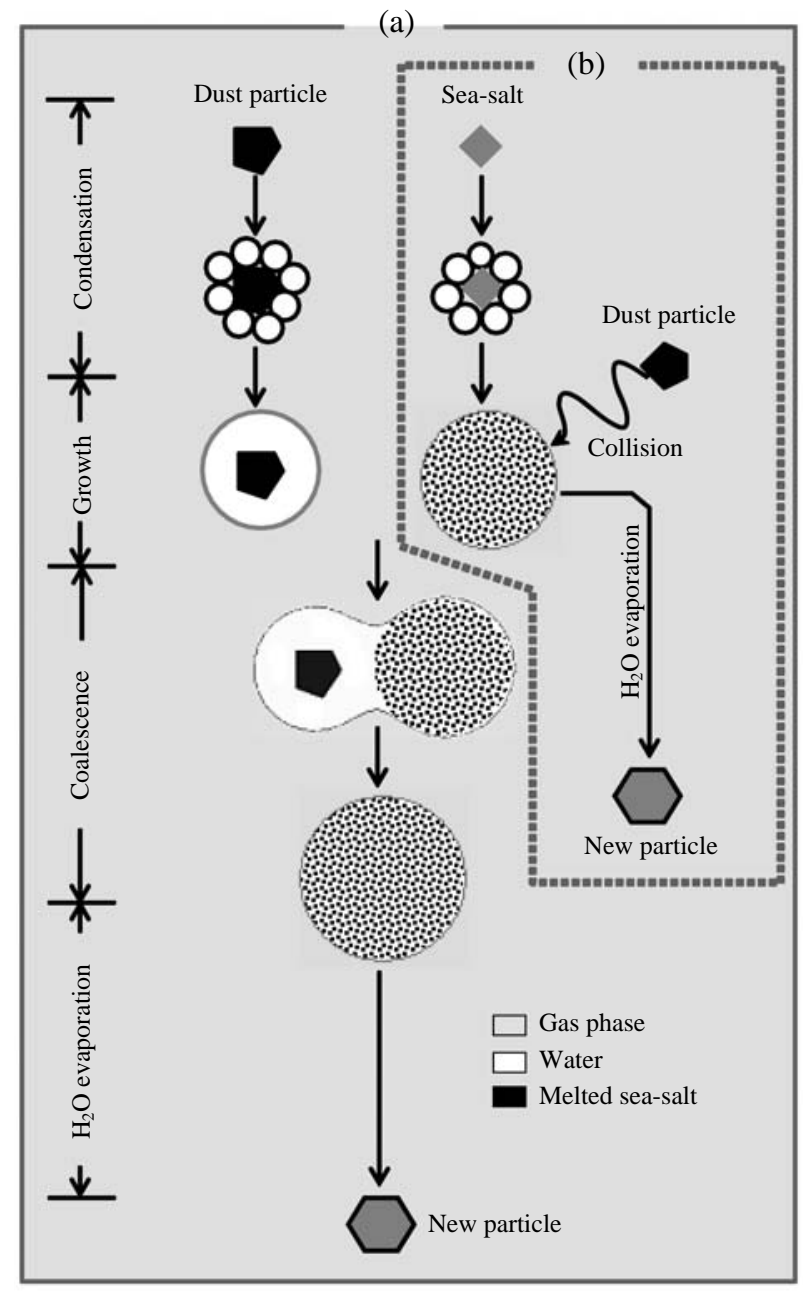

Fig. 8. An illustrative explanation of the transformation processes of the AD particles with sea-salt via nucleation scavenging.

tal distribution. This heterogeneous elemental distribution in an $\mathrm{AD}$ particle might be caused by two dissimilar aging processes (i.e., (a): collision (or coagulation) of dust particles and sea-salts and (b): in-cloud scavenging of both particles). The modification of $A D$ particles occurred most probably due to the collisions and coagulations of dust particles and sea-salts (Zhang and Iwasaka, 2004). Zhang and Iwasaka (2004) suggested that the interaction of AD particles and seasalt is an important process in size and compositional changes of $\mathrm{AD}$ particles during their long range transport, consequently affecting mass transformation and optical properties in the atmosphere. Moreover, a cloud formation process contributes significantly to the chemical modification of AD particles (Ma et al., 2004b). From the study on individual cloud droplets by an X-ray fluorescence microprobe analysis, Ma $e t$ 
Table 2. Quantitatively classified individual AD particles by micro-PIXE net counts.

\begin{tabular}{|c|c|c|c|c|c|c|c|c|}
\hline \multirow[t]{2}{*}{ Particle \# } & \multicolumn{3}{|c|}{$\begin{array}{l}\text { Normalized M-PIXE net } \\
\text { count }(\text { count } / \mathrm{nC})\end{array}$} & \multirow[t]{2}{*}{$\mathrm{a} / \mathrm{b}$} & \multirow[t]{2}{*}{$\mathrm{a} / \mathrm{b}$ of $\mathrm{CJ}-1^{\mathrm{d}}$} & \multirow[t]{2}{*}{$\mathrm{c} / \mathrm{b}$} & \multirow[t]{2}{*}{$\mathrm{c} / \mathrm{b}$ of Ref. } & \multirow[t]{2}{*}{ Classification } \\
\hline & $\mathrm{Na}^{\mathrm{a}}$ & $\mathrm{Si}^{\mathrm{b}}$ & $\mathrm{Cl}^{\mathrm{c}}$ & & & & & \\
\hline 1 & & 260 & 79 & - & - & 0.303 & 0.015 & Aging type 1 \\
\hline 2 & & 7639 & 80 & - & - & 0.010 & 0.015 & Non-aged \\
\hline 3 & & 1232 & 31 & - & - & 0.025 & 0.015 & Aging type 1 \\
\hline 4 & & 410 & 38 & - & - & 0.092 & 0.015 & Aging type 1 \\
\hline 5 & & 614 & 23 & - & - & 0.037 & 0.015 & Aging type 1 \\
\hline 6 & 312 & 1085 & 111 & 0.288 & 0.048 & 0.102 & 0.015 & Aging type 2 \\
\hline 7 & 135 & 2268 & & 0.059 & 0.048 & - & - & Non-aged \\
\hline 8 & & 1246 & 46 & - & - & 0.037 & 0.015 & Aging type 1 \\
\hline 9 & 12 & 3890 & & 0.003 & 0.048 & - & - & Non-aged \\
\hline 10 & 52 & 614 & 20 & 0.085 & 0.048 & 0.033 & 0.015 & Aging type 2 \\
\hline 11 & 7 & 1525 & & 0.005 & 0.048 & - & - & Non-aged \\
\hline 12 & & 994 & 48 & - & - & 0.048 & 0.015 & Aging type 1 \\
\hline
\end{tabular}

d. Standard sample of Chanese loess (Sino-Japan Friendship Centre for Environmental Protection (SJC))

e: Average $\mathrm{Cl} / \mathrm{Si}$ ratio of four kinds Chinese bulk desert sands (Ma et al., 2008)

al. (2004b) reported that a large number of crustal particles were incorporated into cloud droplets during their long-range transport.

Fig. 8 illustrates a presumable explanation for the transformation processes of the AD particles with seasalt by heterogeneous nucleation. Two types of transformation processes of the AD particles can be identified, i.e., the coalescence of two different droplets formed by heterogeneous nucleation on a separated AD particle and a sea-salt ((a) of Fig. 8) and the collision of an $\mathrm{AD}$ particle to the droplet formed by a seasalt nucleation ((b) of Fig. 8). Although AD particles are insoluble in water, they begin to serve as centers with the condensation of water vapor. $\mathrm{AD}$ particles are less soluble than marine of anthropogenic aerosols, their solubility weathered by condensation-evaporation cycles can be increased (Desboeufs et al., 2001). In addition, these homo/heterogeneous nucleation processes can be homomolecular (involving a single species) or heteromolecular (involving two or more species) (Desboeufs et al., 2001).

According to the transformation processes of the AD particles with sea-salt (as illustrated in Fig. 8), the possible reasons of portion-to-portion dissimilarity shown in Fig. 7 (i.e., (a) upper scanned portion: Na, $\mathrm{Si}$, and $\mathrm{Cl}$ and (b) below scanned portion: $\mathrm{Na}$ and $\mathrm{Cl}$ ) of elemental distribution on and/or in an AD particle can be potentially evaluated by below three aging processes of the $\mathrm{AD}$ particles.

As the first aging process ((a) of Fig. 8), both AD and sea-salt particles were transferred into different cloud droplets via nucleation scavenging. This in-cloud scavenging of particles is called rainout. During this rainout processes, sea-salt particles were perfectly melted; however, hydrophobic AD particle were keep- ing a horizontal water film on its surface (Desboeufs et al., 2001). Both cloud droplets were then consolidated, when they grew and diffuse in cloud layer. Finally, descending air parcel by high pressure and evaporation of water from cloud droplet made a new particle which contained partially sea-salt crystal on its surface.

As the second aging process ((b) of Fig. 8), an AD particle that did not take up any water (i.e., it cannot be dissolved in cloud droplet by itself) was scavenged by a cloud droplet (i.e., through collision) formed by rainout of sea-salt. Then a chemically different particle was born.

As distinct from nucleation scavenging, the collisions and coagulations of an AD particle and a seasalt can be thought as the third aging process. This homogeneous particle-to-particle reaction is probably due to the modification of AD particle.

\subsection{Quantitatively Classified Individual AD Particles by Micro-PIXE Net Counts}

Besides the morphological grouping of individual AD particles discussed above, we made another attempt to classify individual AD particles by micro-PIXE net counts. Energy of the detected X-ray is converted in the pulse (count) processing electronics to the voltage pulse delivered at the output of the spectroscopy amplifier. This is an analog signal (pulse amplitude) which has to be converted to a digital number in a device called multichannel analyzer (MCA). The MCA spectrum consists of a certain number of channels which number is a linear function of X-ray energy. Each channel is actually a counter that counts events in the corresponding energy interval, forming the final energy spectrum on the MCA screen (IAEA-TEC- 


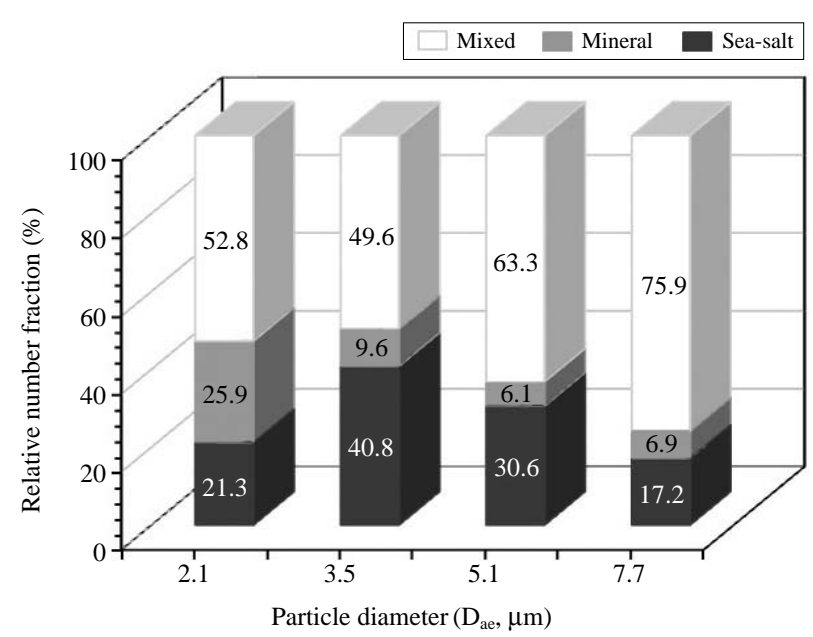

Fig. 9. Relative number fraction of each particle type in the size-classified particles collected during AD event.

DOC-1190, 2000).

In order to obtain the actual net count originated from an $\mathrm{AD}$ particle, the integrated X-ray counts of background (filter blank) was subtracted from the gross count containing that of an $\mathrm{AD}$ particle. Then the net count was normalized by the current (count $/ \mathrm{nC}$ ) that was measured directly from the rotating vane which intercepts the beam certain percentage of the total time. From the normalized net count, the quantitative classification of individual AD particles was attempted and the result was summarized in Table 2. From the calculation and comparison of the relative ratios of X-ray net count for three elements $(\mathrm{Na}, \mathrm{Si}$, and $\mathrm{Cl}$ ) in $\mathrm{AD}$ particles, individual $\mathrm{AD}$ particles $(50 \%$ cut off size: $3.5 \mu \mathrm{m})$ can be classified into three distinct groups (i.e., Aging types 1-2, and non-aged type). The aging processes of each type can be classified as follows;

Aging type 1: AD particle was coated by the gaseous $\mathrm{Cl}$ evaporated by the reaction between artificial acids (e.g., sulfuric acid \& nitric acid) and sea salt.

Aging type 2: AD particle was mixed with sea salt but no additional reaction with artificial acids was done.

As another possible aging type, it can be thought that $\mathrm{AD}$ particle is mixed with sea salt and then $\mathrm{Cl}$ is partially evaporated after reaction between this mixed particle and artificial acids. However, this aging type of $\mathrm{AD}$ particle was not observed for the target particles of this study.

Fig. 9 shows the relative number fraction of each particle type as a function of aerodynamic particle size. 150 particles were randomly selected from each size of particle and were radiated by a microbeam. The chemically transformed AD particles with marine components accounted for $49.6 \%$ to $75.9 \%$ (average level of $60.4 \%)$ in full size-range $(2.1-7.7 \mu \mathrm{m})$ of particles. Larger particles (greater than $5.1 \mu \mathrm{m}$ in diameter) tend to be effectively aged. On the other hand, relatively smaller fraction $(<3.5 \mu \mathrm{m})$ did not go through sufficient transformation processes. On the basis of this particle size dependence of AD particle's mixing ratio, Zhang et al. (2003) reported the similar results obtained from SEM-EDX analysis of size-resolved particles collected during AD event at Nagasaki located at the west of the island of Kyushu.

As mentioned earlier, the chemical modification of AD particle with sea-salt occurred most probably by the particle-to-particle collisions, coagulations, and coalescence of cloud droplets. In order to thoroughly estimate the particle-to-particle (or cloud droplet-tocloud droplet) collision and coalescence of cloud droplets, though one has to consider a large number of parameters such as particle (cloud droplet) radii, particle (cloud droplet) number concentrations, particle (cloud droplet) settling speeds, vigorousness of turbulence in ambient (cloud), vertical velocities generated by turbulence in ambient (cloud), horizontal velocity of the fluid in ambient (cloud), uniformity of fluid mixing in ambient (cloud) (Blanchette, 2003), it can be suggested that larger particles might be expected to be more frequently experienced collision with sea-salt.

\section{CONCLUSIONS}

In spite of the distinct merits of micro-PIXE in analytical chemistry, scientific uncertainties about chemical transformation of $\mathrm{AD}$ particles by reaction with sea-salt remain because the detection of light elements (atomic number $<14$ ) by micro-PIXE has not been practiced sufficiently. In this study, by a combination of two different detector systems of micro-PIXE, a broad detection range of elements including $\mathrm{Na}, \mathrm{Mg}$, and $\mathrm{Al}$ was successively realized. The well drawn elemental spectra and maps from this novel attempt enabled us to visually classify individual $\mathrm{AD}$ particles. It was also possible to sufficiently interpret the mixing state of individual AD particles with sea-salts, especially portion-to-portion dissimilarity of chemical state in individual AD particles. In addition to this, the detailed information of elemental micro distribution obtained from the scanning of microbeam with a 1-2 $\mu \mathrm{m}$ beam diameter in and/or on an AD particle helped us presume the aging processes of $\mathrm{AD}$ particles both in ambient and in-cloud. The relative number fraction of chemically transformed particle type in the size-classified particles collected during AD event indicates that the chemical mixing states of individual 
AD particles are strongly dependent on particle size. However, due to the limitation of particles that were subject to the novel micro-PIXE analysis, we were not able to estimate all the properties of the entire AD particle. Hence, it should be examined how well our result of single $\mathrm{AD}$ particle analysis can represent the properties of the whole AD particles.

\section{ACKNOWLEDGEMENTS}

The author wishes to express thanks to all the members, especially Mr. T. Sakai, in the Advanced radiation technology center, Japan Atomic Energy Research Institute for their help of micro-PIXE analysis. The author gratefully acknowledges Professor M. Kasahara at Institute of Science and Technology Research, Chubu University for his planning and arrangement of micro-PIXE experiment for a long period. The author also acknowledges the NOAA Air Resources Laboratory (ARL) for the provision of the HYSPLIT transport and dispersion model and/or READY website (http:// www.arl.noaa.gov/ready.html) used in the present study.

\section{REFERENCES}

Blanchette, F.A. (2003) Sedimentation in a Stratified Ambient. Thesis of doctor of philosophy of Department of Mathematics. Massachusetts Institute of Technology, pp. 1-156.

Desboeufs, K.V., Losno, R., Colin, J.L. (2001) Factors influencing aerosol solubility during cloud processes. Atmospheric Environment 35, 3529-3537.

Duce, R.A., Unni, C.K., Ray, B.J., Prospere, J.M., Merrill, J.T. (1980) Long-range atmospheric transport of soil dust from Asia to the tropical north Pacific: Temporal variability. Science 209, 1522-1524.

Gieray, R., Wieser, P., Engelhardt, T., Swietlicki, E., Hansson, H.-C., Mentes, B., Orsini, D., Martinsson, B., Svenningsson, B., Noone, K.J., Heintzenberg, J. (1997) Phase partitioning of aerosol constituents in cloud based on single-particle and bulk analysis. Atmospheric Environment 31, 2491-2502.

Hwang, H.J., Kim, H.K., Ro, C.U. (2008) Single-particle characterization of aerosol samples collected before and during an Asian dust storm in Chuncheon, Korea. Atmospheric Environment 42, 8738-8746.

International Atomic Energy Agency (IAEA)-TECDOC1190 (2000) Instrumentation for PIXE and RBS, pp. 178.

Iwasaka, Y., Yamamoto, M., Imasu, R., Ono, A. (1988) Transport of Asian dust (KOSA) particles: importance of weak KOSA events on the geochemical cycle of soil particles. Tellus 40B, 494-503.

Johansson, S.A.E., Campbell, J.L. (1988) PIXE: A novel technique for elemental analysis. John Wiley and Sons, New York, pp. 134-140.

Koltay, E., Rajta, I., Morales, J.R., Borbely-Kiss, I., Kiss, A.Z. (1999) Characterization of individual eerosol particles from the eruption of Lonquimay volcano in Chile. Nuclear Instruments and Methods in Physics Research B 1150, 375-383.

Ma, C.-J., Kasahara, M., Hwang, K.C., Choi, K.C., Choi, S.B., Lee, J.J. (2000) Physicochemical characteristics of single Asian dust storm particles. Journal of Korean Society for Atmospheric Environment 16E, 29-38.

Ma, C.-J., Kasahara, M., Tohno, S., Kim, K.-H. (2008) Physicochemical properties of Asian dust sources. Asian Journal of Atmospheric Environment 2(1), 26-33.

Ma, C.-J., Tohno, S., Kasahara, M., Hayakawa, S. (2004a) Properties of individual Asian dust storm particles collected at Kosan, Korea during ACE-Asia. Atmospheric Environment 38, 1133-1143.

Ma, C.-J., Tohno, S., Kasahara, M., Hayakawa, S. (2004b) Properties of the size-resolved and individual cloud droplets collected in the western Japan during Asian dust storm event. Atmospheric Environment 38, 45194529.

Ma, C.-J., Oki, Y., Tohno, S., Kasahara, M. (2004c) Assessment of wintertime atmospheric pollutants in an urban area of Kansai, Japan. Atmospheric Environment 38, 2939-2949.

Ma, C.-J., Kim, K.-H. (2008) A combination of size-resolved particle samplers and XRF microprobe technique for single particle study. Atmospheric Environment 42, 7022-7026.

Nishikawa, M., Kanamori, S. (1991) Chemical composition of Kosa aerosol (yellow sand dust) collected in Japan. Analytical Science 7, 1127-1130.

Odom, R.W., Lux, G., Fleming, R.H., Chu, P.K., Niemeyer, I.C., Blattner, R.J. (1988) Quantitative trace element analysis of microdroplet residues by secondary ion mass spectrometry. Analytical Chemistry 60, 2070-2080.

Sakai, T., Oikawa, M., Sato, T. (2005) External scanning proton microprobe - a new method for in-air elemental analysis. Journal of Nuclear and Radiochemical Sciences 6(1), 69-71.

Zhang, D., Iwasaka, Y. (2004) Size change of Asian dust particles caused by sea salt interaction: Measurements in southwestern Japan. Geophysical Research Letters 31, L15102, doi:10.1029/2004GL020087.

Zhang, D., Iwasaka, Y., Shi, G., Zang, J., Matsuki, A., Trochkine, D. (2003) Mixture state and size of Asian dust particles collected at southwestern Japan in spring 2000. Journal of Geophysical Research 108, 4760, doi: 10.1029/2003JD003869.

(Received 13 July 2010, accepted 27 August 2010) 